\title{
AVALIAÇÕES NACIONAIS, CURRÍCULO DA ESCOLA BÁSICA E A PRODUÇÃO DO ALUNO DISTORÇÃO IDADE X SÉRIE
}

\author{
Marcelo Ribeiro de Mesquita \\ Wladirson Ronny da Silva Cardoso ${ }^{(*)}$
}

Vivemos tempos temerosos no Brasil. Visualiza-se um contexto político contido na agenda neoliberal de queimar na fornalha do capital internacional os trabalhadores, com a destruição de direitos conquistados, congelamentos de investimentos públicos, arrocho salarial, intervenções das Forças Armadas nos estados sob o pretexto de conter a violência que, aliás, não mostra sinais de declive, pelo contrário. Aliado a isto, no campo social, percebe-se um movimento ultraconservador que assola o país e no qual proliferam os discursos do ódio às minorias.

A par disso, a educação não passaria incólume. Tendo em vista se tratar de uma política fundamental do estado neoliberal, a educação vem passando por grandes reformas nas últimas décadas, principalmente nos países chamados emergentes, os quais seguem as orientações de organismos internacionais, como a Unesco e o Banco Mundial.

Lopes (2012) afirma que as políticas educacionais nacionais ganham centralidade na década de 1990 no Brasil. A emergência de tais políticas estava consoante com a agenda neoliberal cuja visão determinista da história caracteriza o estágio atual do capitalismo: o "neoliberalismo que Socialmente [...] conseguiu muitos dos seus objetivos, criando sociedades marcadamente mais desiguais, embora não tão desestatizadas como queria”. (ANDERSON, 1995, p. 06). O neoliberallismo, desta forma, está para além da visão econômica ou puramente de mercado e sim como projeto de sociedade que subjetiva e opera práticas discursivas de naturalização da desigualdade social.

Neste sentido, as reformas sociais, entre elas a educação, atingem diretamente o cotidiano das escolas que, por sua vez, são um dos palcos fundamentais para implementá-las, visto que é uma das instituições do estado em que o sujeito passa uma parte considerável do tempo de sua vida.

Buscaremos, então, neste texto, analisar a influência das avaliações nacionais de larga escala e seus efeitos nos currículos das escolas e na produção do aluno com distorção idade x série,

\footnotetext{
${ }^{(*)}$ Marcelo Ribeiro de Mesquita. Mestrando do Programa de Pós-graduação em Currículo e Gestão da Escola Básica (PPEB) do Núcleo de Estudos Transdisciplinares em Educação Básica (NEB) da Universidade Federal do Pará (UFPA) na linha de Currículo da Educação Básica.

Wladirson Ronny S. Cardoso. Docente da Universidade do Estado do Pará e do Programa de Pós-graduação em Currículo e Gestão da Escola Básica (PPEB) do Núcleo de Estudos Transdisciplinares em Educação Básica (NEB) da Universidade Federal do Pará (UFPA).
} 
também cunhado como fracassado ou problema. Para tanto, utilizamos, num primeiro momento, a metodologia genealógica de Foucault com intuito de discutir a maquinaria escolar estando a serviço de um modo de produção, o capitalismo. Inspirado em Nietzsche, à genealogia foucaultiana não tem como interesse a busca de uma origem, como se poderia pensar pela etimologia da palavra. Nem tampouco a busca interminável de precursores.

Foucault utilizou-se da genealogia para pensar o presente. Para Gregorin (2017) Foucault estava preocupado em realizar uma ontologia crítica do presente. Em outras palavras, quais os processos de subjetivação e objetivação nos torna o que somos hoje. Para tal, ele realiza um percurso histórico de emergência de saberes (arqueologia) e pela genealogia dos poderes.

Contudo, não trata a história seguindo uma linearidade: estudar o passado para desvendar o presente e prescrever o futuro. Não era essa sua intenção, mas sim estudar o presente nas descontinuidades históricas, nos processos de ruptura que são os imperativos históricos que vão criar os microdispositivos para pensar nossa contemporaneidade. Segundo ele, "a emergência é, portanto, a entrada em cena das forças; é sua interrupção, o salto pelo qual elas passam dos bastidores para o teatro, cada uma com seu vigor e sua juventude”. (FOUCAULT, 2015, p. 67).

A genealogia seria, portanto:

[...] com relação ao projeto de uma inscrição dos saberes na hierarquia de poderes próprios á ciência, um empreendimento para libertar da sujeição os saberes históricos, isto é, torná-los capazes de oposição e de luta contra a coerção de um discurso teórico, unitário, formal, e cientifico. A reativação dos saberes locais - menores, diria talvez Deleuze - contra a hierarquização científica do conhecimento e seus efeitos intrínsecos de poder, eis o projeto dessas genealogias desordenadas e fragmentárias. (FOUCAULT, 2015, p. 270).

Neste sentido, é em sua obra vigiar e punir, por exemplo, que o filósofo nos mostra, através de fartos documentos e acontecimentos históricos, que passamos de uma sociedade punitiva, na qual eram comuns espetáculos públicos de punição dos condenados, para uma sociedade disciplinar.

Na sociedade punitiva o corpo era visivelmente o alvo principal do apenado. A passagem para sociedade disciplinar, então, deixou de agir sobre o corpo?

O corpo: superfície de inscrição dos acontecimentos (enquanto a linguagem os marca e as ideias os dissolvem), lugar de dissociação do Eu (que supõe a quimera de uma unidade substancial) volume em perpétua pulverização. A genealogia, como análise da proveniência, está, portanto, no ponto de articulação do corpo com a história. Ela deve 
mostrar o corpo inteiramente marcado de história e a história arruinando o corpo. (FOUCAULT, 2015, p. 65).

Desta forma, a sociedade disciplinar não deixou de agir sobre o corpo, mas fabricou técnicas sutis para controlá-lo. As instituições, por exemplo, como a prisão, o manicômio, a escola e outros realizam de forma microscópica o controle dos corpos. São nos corpos que são produzidas as subjetividades. Não à toa, a escola possui todo um ordenamento do tempo e do espaço que visa agir, vigiar e punir o corpo.

Nesse viés, para alcançar o intento de uma ontologia histórica do presente no âmbito escolar, isto é, como é a escola hoje? Para tanto, num segundo momento discutiremos como as avaliações nacionais têm induzido os currículos das escolas e a consequente fabricação do aluno em distorção idade x série. Para alcançar este intuito, lançaremos mão dos dados obtidos na pesquisa de campo realizada em um projeto de aceleração da aprendizagem em uma escola Estadual denominado de "Mundiar" e dos dados de um projeto chamado ALFAMAT colhidos em uma escola municipal. Ambas as escolas localizam-se em áreas periféricas de Belém do Pará.

\section{O IMPERATIVO HISTÓRICO DE EMERGÊNCIA DA EDUCAÇÃO ESCOLAR}

Foucault não escreveu nenhum texto específico sobre a escola. No entanto, ao realizar a genealogia das tecnologias disciplinares, principalmente, em Vigiar e Punir, o autor observou que a escola tornou-se uma importante engrenagem para constituição de um poder disciplinar. Em torno da invenção da escola como espaço de disciplinarização ele nos mostra que:

Pouco a pouco - mas principalmente depois de 1762 - o espaço escolar se desdobra; a classe se torna homogênea, ela agora só se compõe de elementos individuais que vêm se colocar uns ao lado dos outros sob os olhares do mestre. A ordenação por fileiras, no século XVIII, começa a definir a grande forma de repartição dos indivíduos na ordem escolar: filas de alunos na sala, nos corredores, nos pátios; colocação atribuída a cada um em relação a cada tarefa e cada prova; colocação que ele obtém de semana a semana, de mês em mês, de ano em ano; alinhamento das classes de idade umas depois das outras; sucessão dos assuntos ensinados, das questões tratadas segundo uma ordem de dificuldade crescente. E, nesse conjunto de alinhamentos obrigatórios, cada aluno segundo sua idade, seus desempenhos, seu comportamento, ocupa ora uma fila, ora outra; ele se desloca o tempo todo numa série de casas; umas ideais, que marcam uma hierarquia do saber ou das capacidades, outras devendo traduzir materialmente no espaço da classe ou do colégio essa repartição de valores ou dos méritos. Movimento perpétuo onde os indivíduos substituem uns aos outros, num 
espaço escondido por intervalos alinhados. A organização de um espaço serial foi uma das grandes modificações técnicas do ensino elementar. Permitiu ultrapassar o sistema tradicional (um aluno que trabalha alguns minutos com o professor, enquanto fica ocioso e sem vigilância o grupo confuso dos que estão esperando). Determinando lugares individuais tornou possível o controle de cada um e o trabalho simultâneo de todos. Organizou uma nova economia do tempo de aprendizagem. Fez funcionar o espaço escolar como uma máquina de ensinar, mas também de vigiar, hierarquizar, de recompensar". (FOUCAULT, 2014, p. 144).

A partir destas pistas conceituais é possível perceber que a escola nem sempre existiu, mas que foi inventada num determinado contexto histórico e por imperativos discursivos que a moldaram e a tornaram numa engrenagem a serviço do modo de produção emergente, qual seja: o capitalismo, para fabricar o trabalhador produtivo, ocupando o tempo ocioso e subjetivando o corpo dócil e disciplinado através do que o filósofo Francês denominou de Governamentalidade ou tecnologias de governo do eu.

Retomaremos o conceito de Governamentalidade para discorrer acerca da escola como um dispositivo da arte de governar. Nesta perspectiva, a escola se constitui em um Locus privilegiado da governamentalidade, pois:

A partir da noção de governamentalidade é possível, por exemplo, compreender melhor a razão que levou os Estados modernos a tomarem a educação escolar como uma instituição privilegiada, concedendo especial atenção ao estabelecimento de seus objetivos e de suas formas de funcionamento. Conforme um de nós argumentou há quase uma década (VEIGA-NETO, 2000), pode-se dizer que a escola coloca-se na interseção entre o jogo do pastor e o jogo da cidade (FOUCAULT, 1988, 2006). Inteiramente afinada com a racionalidade política moderna, ela totaliza, ao mesmo tempo em que individualiza; isso é, se por um lado a escola constitui individualidades singulares, criando subjetividades que se pensam únicas e indivisíveis, ela também cria posições de sujeito subordinadas a um todo social, fora das quais cada sujeito nem mesmo faz sentido. (VEIGA-NETO; SARAIVA, 2011, p. 9).

Partindo desta discussão, Varela e Alvarez-Uria (1992) discutem como a escola surgiu e as condições históricas que lhe tornaram uma "maquinaria" indispensável ao modo de produção capitalista. Note-se tal importância quando nos referimos às sociedades sem escolas, ou pelo menos sem esse lócus específico de transmissão do conhecimento, são cunhadas como primitivas ou bárbaras e sem civilidade. A escola naturalizou-se tanto que já não enxergamos que ela foi inventada, visto que: 
A escola nem sempre existiu; daí a necessidade de determinar suas condições históricas de existência no interior de nossa formação social. Que caracteriza fundamentalmente esta instituição que ocupa o tempo e pretende imobilizar no espaço todas as crianças compreendidas entre seis e dezesseis anos? Na realidade esta maquinaria de governo da infância não apareceu de súbito, mas, ao invés disso, reuniu e instrumentalizou uma série de dispositivos que emergiram e se configuraram a partir do século XVI. (VARELA; ALVAREZ-URIA, 1992, p. 14.).

Seguindo este caminho, os autores propõe a aplicação do método genealógico com intuito de interpelar o passado e que nos auxilie a interpretar o presente. No entanto, entendendo que o passado não segue uma linearidade em relação ao presente. Assim, investigar o passado para descobrir as continuidades e descontinuidades e a observar os processos que ligam a escola a determinados sistemas de poder e como eles se disfarçam ou se transformam.

A par disso, os autores apontam o fanatismo religioso como a chave para entender a modernidade. É a partir da necessidade de "Cristianização" das crianças que surge um novo estatuto da infância: a separação da infância dos adultos e a imperiosa necessidade de governava-la. Assim, as crianças serão enclausuradas em espaços que começam a graduar por idade e o ensinamento da obediência a Deus, aos padres, reitores, professores etc. É neste momento histórico que "Rousseau pode redefinir a infância como idade 'psicológica' com etapas às quais correspondem necessidades e interesses, e em consequência suscetíveis de uma educação diferenciada" (VARELA; ALVAREZ-URIA, 1991, p. 73).

À luz desta perspectiva, Popkewitz (2010) realizou um estudo acerca da infância e da escolarização na virada do século XX até o presente. Para este autor, o tema da salvação da infância persistiu ao longo das reformas contemporâneas, no entanto, a criança agora deve ser salva de viver fora do espaço cultural cosmopolita e, portanto, deve adquirir qualidades associadas à aprendizagem ao longo da vida. Assim:

O cosmopolitismo do presente dirige a atenção às qualidades da criança associadas à aprendizagem ao longo da vida, que se posiciona em relação aos medos da criança que vive fora do espaço cultural desse mesmo cosmopolitismo; a criança classificada como urbana pobre e em desvantagem, criança que não tem as capacidades para entrar na média, em que todas as crianças aprendem. Tanto no passado quanto no presente, as matérias escolares são usadas como exemplos para explorar os princípios por meio dos quais os gestos dúbios de esperança e medo - inclusão e exclusão - são incorporados na escolarização. (POPKEWITZ, 2010, p. 79). 
Vertendo neste momento para o Brasil, a genealogia da emergência da escola ${ }^{1}$ como instituição indispensável para o progresso do país surge como imperativo histórico na passagem do Império para a República.

Fazendo um recorte neste período histórico no Brasil, é possível observar as condições de emergências da escola.

Para Gregolin (2017), no final do século XIX, o Brasil passava por grandes transformações históricas e estes acontecimentos moldariam de forma determinante um novo país. Havia neste momento a passagem de um regime monárquico para um regime republicano; a abolição da escravatura que modificava as relações de trabalho no Brasil e a chegada dos imigrantes para substituir a mão-de-obra escrava e muito mais qualificada que os antigos escravos.

É neste contexto, portanto, que passamos de um país rural para um país prioritariamente urbano e industrializado. A par disso, o ideário republicano, de base positivista, reivindicava principalmente as ideias ligadas ao progresso e civilidade. Surge desta forma, a urgência de uma identidade brasileira que não possuísse mais ligação com Portugal, visto que o Brasil não era mais colônia e não possuía mais uma realeza portuguesa. Agora se tratava de uma nação independente e que precisava construir sua identidade.

Neste momento histórico que a escola terá sua centralidade para responder as necessidades de construção do progresso e civilidade que o país precisava, visto que a educação e a saúde eram a força motriz desse progresso. As ideias higienistas de Carlos Chagas, por exemplo, moviam o ideário de um povo saudável, enquanto a escola fazia parte importante da reforma como instituição capaz de produzir o sujeito civilizado.

A partir destas ideias de progresso, as cidades serão remodeladas e as paisagens urbanas mudariam drasticamente. Baseados nas ideias europeias de progresso, grandes prédios suntuosos serão construídos e, muitos deles, para abrigar escolas, que serão o carro frente do progresso.

É assim, por exemplo, que teremos um reordenamento das práticas pedagógicas, na qual, a língua portuguesa ganhará centralidade na construção da identidade nacional. Todas as outras línguas que ainda eram pronunciadas no Brasil foram proibidas e foi instituída a língua portuguesa, principalmente por ser europeia, se tornou a base do currículo, e até hoje permanece.

A escola, portanto, estava como uma das prioridades na agenda republicana, pois seria a instituição responsável pelo progresso do país, além de garantir a unidade da República, aliada a

\footnotetext{
${ }^{1}$ O objetivo aqui não será discutir origem de escolas no Brasil colônia com os Jesuítas, mas sim como a educação escolar tornou-se obrigatória no Brasil a partir da passagem do Império para a República.
} 
ideia de nação e pátria. Para Le Goff (2013, p. 75) "este sentimento sempre esteve vivo nas nações e nos povos que ainda não tinham podido concretizar sua unidade nacional: a ideia de nação, como é natural, é especialmente querida dos povos que ainda não eram politicamente unidos”.

É válido ressaltar ainda que o Brasil, que até então possuía a maioria da população vivendo no campo, começa a desenvolver as suas indústrias, fato que modificará o cenário: o processo de urbanização surge. As populações do campo começam a migrar para a cidade. Era necessário, portanto, controlar esta população que estava chegando. E a escola tornou-se uma engrenagem importante.

Nesta perspectiva, a escola sempre foi o palco de muitas reformas que aconteceram ao longo do século XX e, com isso, sofisticando suas formas de controle e governo das populações. Depois de realizar esta genealogia da escola, realizaremos um salto cronológico para discutir o presente da escola no que tange as políticas de avaliação em larga escala no Brasil e como isto tem induzido os currículos da escola básica.

\section{AVALIAÇÕES EM LARGA ESCALA NO BRASIL E O CURRÍCULO DA ESCOLA BÁSICA}

A forma de operacionalizar essa racionalidade política para produção de subjetividades "dóceis", como discutimos anteriormente, e que saibam governar a si no âmbito da educação é através do currículo, pois na trajetória formativa dos alunos estão intrínsecas relações de poder e disputas em torno do que ensinar e o que será produzido ao final do percurso. E aí esta em jogo a escolha de conteúdos de acordo com uma visão de sujeito que se quer construir para determinada sociedade. Assim

O Currículo (ou eu poderia usar o conceito mais amplo de pedagogia) existe no interior de uma instituição chamada escola, que é uma invenção relativamente recente da sociedade ocidental. [...] O currículo, pois, pode ser visto como uma invenção da modernidade, a qual envolve formas de conhecimento cujas funções consistem em regular e disciplinar o indivíduo [...] a ideia de currículo corporifica uma organização particular do conhecimento pela qual os indivíduos devem regular e disciplinar a si próprios como membros de uma comunidade/sociedade. [...] o currículo é uma imposição do conhecimento do "eu" e do mundo que propicia ordem e disciplina aos indivíduos. A imposição não é feita através da força bruta, mas através da inscrição de sistemas simbólicos de acordo com os quais a pessoa deve interpretar e organizar o mundo e nele agir. (POPKEWITZ, 1994, p.186). 
O currículo, neste sentido, visa produzir determinadas identidades mediadas, principalmente, pelos conteúdos escolares.

Seguindo esta interpretação, o aluno que não consegue acompanhar estes conteúdos sofre, no seu itinerário escolar, inúmeras repetências, casos de evasão ou outras situações que o colocam como "atrasado" que, por sua vez, reflete-se na visão que se vai ter deste, pois se transformará no chamado "aluno problema" para escola e, mais ainda, para os alunos que frequentam as escolas sob a cunha de periferia.

Tendo em vista essa perspectiva de currículo, como uma prática discursiva que produz efeitos de poder, foi promulgada a Base Nacional Comum Curricular (BNCC) que passou por três versões preliminares e cuja versão final ficou muito distante do que se esperava. Em nota, a Anped (2017) criticou a metodologia de construção que denomina de obscurantista. No que tange ao documento final a base é muito criticada por conter uma visão fragmentada do conhecimento e não debater questões importantes que as escolas não podem deixar de discutir, como as relações de gênero.

É a BNCC que deve orientar a construção dos currículos escolares pelos próximos anos. Na secção intitulada Os fundamentos pedagógicos da BNCC o documento deixa claro as concepções de sociedade e de formação do sujeito: para a governamentalidade neoliberal, pois traz

Foco no desenvolvimento de competências. O conceito de competência, adotado pela BNCC, marca a discussão pedagógica e social das últimas décadas e pode ser inferido do texto da LDB, especialmente quando se estabelecem as finalidades gerais do Ensino Fundamental e do Ensino Médio [...] Ao adotar esse enfoque, a BNCC indica que as decisões pedagógicas devem estar orientadas para o desenvolvimento de competências. Por meio da indicação clara do que os alunos devem "saber" (considerando a constituição de conhecimentos, habilidades, atitudes e valores) e, sobretudo, do que devem "saber fazer" (considerando a mobilização desses conhecimentos, habilidades, atitudes e valores para resolver demandas complexas da vida cotidiana, do pleno exercício da cidadania e do mundo do trabalho) a explicitação das competências oferece referências para o fortalecimento de ações que assegurem as aprendizagens essenciais definidas na BNCC. (BRASIL, 2017, p. 13).

A BNCC traz em seu bojo concepções definidas por organismos internacionais como a Unesco (que foi a responsável pelo relatório Jacques Delors acerca da educação, um tesouro a descobrir) e a OCDE que elabora o PISA (Programa Internacional de Avaliação dos Estudantes) e que é fio condutor de políticas curriculares, inclusive no Brasil no qual a Prova Brasil é baseada e 
que tem determinado o currículo das escolas. Assim, antes da aprovação da BNCC, a Prova Brasil já determinava o que deve ser ensinado nas escolas.

Neste momento, então, discutiremos a avaliação de larga escala, como a PROVA BRASIL como indutora do currículo.

A Prova Brasil faz parte do SAEB, o Sistema de Avaliação da Educação Básica, mais especificamente a Anresc que é a Avaliação Nacional do Rendimento Escolar e que, juntamente com os dados de evasão e repetência das escolas no Brasil, gera a nota que compõe o Índice de Desenvolvimento da educação Básica (Ideb) e tem como objetivo medir a qualidade da educação no Brasil, numa escala que varia de 0 a 10, sendo estipulada a nota mínima de 6,0 até 2022 por se tratar das notas dos chamados Países Desenvolvidos (INEP, 2011).

A nota do Ideb é composta pelas notas da Prova Brasil - aplicada a cada dois anos nas escolas públicas brasileiras - contém questões de Língua Portuguesa e Matemática que avaliam os chamados descritores, que são as habilidades que os alunos devem dominar ao final do $5^{\circ}$ e $9^{\circ}$ ano do Ensino Fundamental e $3^{\circ}$ ano do Ensino Médio - e pelos índices de evasão e repetência que as escolas enviam ao Ministério da educação através do Censo escolar anualmente. De acordo com $\operatorname{INEP}(2015)$ :

A Anresc (Prova Brasil), ANEB e ANA são avaliações elaboradas a partir de matrizes de referência. Os conteúdos associados a competências e habilidades para cada série e para cada disciplina foram subdivididos em partes menores, cada uma especificando o que os itens das provas devem medir - estas unidades são denominadas "descritores". Esses, por sua vez, traduzem uma associação entre os conteúdos curriculares e as operações mentais desenvolvidas pelos alunos. Os descritores, portanto, especificam o que cada habilidade implica e são utilizados como base para a construção dos itens dos itens de diferentes disciplinas. (INEP, 2015. Disponível em <www.provabrasil.inep.gov.br/escalas-de-proficiência>. Acesso em 12/06/2018).

Outra questão importante nessa avaliação realizada pelo Inep diz respeito ao controle do tempo para realização das provas. A metodologia para aplicação da Prova segue um ritual rigoroso. São quarenta e quatro questões divididas em quatro blocos com onze questões em cada. Dois blocos de língua portuguesa e dois blocos de matemática. Portanto, vinte e duas questões para cada disciplina. Então, esses descritores têm induzido os currículos escolares e as práticas pedagógicas em sala de aula com os alunos, ainda que seja feita uma ressalva pelo próprio Instituto que os descritores não englobam todo o currículo escolar e não devem ser confundidas com estratégias ou orientações, mas é justamente isto que tem acontecido na grande maioria das Redes de Ensino 
Públicas pelo Brasil, uma vez que boas notas no Ideb implicam recursos para as escolas e governos, além de uma disputa entre as próprias escolas, gerando uma espécie de ranking, no qual as escolas com as maiores notas são premiadas por suas respectivas secretarias. Neste sentido, as formações continuadas de professores tem seguido essa lógica.

Como exemplo, no âmbito da Rede Municipal de Ensino de Belém do Pará foi implementado desde 2009 o programa ALFAMAT ${ }^{2}$ cujo objetivo consiste em realizar oficinas pedagógicas aos professores do ciclo II (equivalente ao $4^{\circ}$ e $5^{\circ}$ ano) acerca dos descritores da Prova Brasil. Inclusive o planejamento curricular dos professores deve seguir exatamente a ordem dos descritores determinados pelo programa, visto que serão objetos de avalição nas provas elaboradas pelo programa ALFAMAT e mandado direto para as escolas, conforme nos relataram os professores entrevistados que asseveram que inclusive podem perder a turma na qual lecionam se os resultados não forem satisfatórios e que, inclusive, as escolas municipais que conseguiram maiores notas do Ideb foram premiadas com recursos e materiais pedagógicos.

Nesta perspectiva, a autonomia docente está sendo vigiada. A aparente liberdade que os docentes supunham ter na escolha dos conteúdos escolares que compõe o currículo, na verdade é cercada pela vigilância dos experts que determinam o que pode ou não constar como conteúdos.

Para Coutinho e Sommer (2011, p. 87) “os professores contemporâneos têm compartilhado um conjunto de certezas que articulam seu pertencimento a um ideário pedagógico identificado como crítico, radical, emancipatório, transformador".

O Projeto político Pedagógico da Escola foi atualizado pela última vez em 2014, ou seja, anterior a BNCC. Todavia, ao analisar a citação da BNCC e a que consta no PPPE da escola, é possível inferir que ambos partem da ideia de um sujeito a priori, com uma essência universal que precisa ser transformada para agir na sociedade.

Assim para os dois autores, essas ideias guardam ligação com uma visão escolanovista de produção de um sujeito autônomo, capaz de autogovernar-se. Os autores enfatizam que foi através da criação do Instituto de Educação fundado no Rio de janeiro que propiciou o desenvolvimento no país da cientificidade da educação tendo como base os saberes da Biologia, da Sociologia e da Psicologia e que até hoje moldam os discursos docentes. Para eles, o instituto de Educação sempre "Esteve envolvido na produção e circulação da ideia de que a escola tradicional deveria ser

\footnotetext{
${ }^{2}$ O programa ALFAMAT (Alfabetização em Português e Matemática) é uma formação continuada realizada pelo Núcleo de Informática Educativo (NIED) da Rede Municipal de ensino de Belém em que os professores são obrigados a frequentar as oficinas nos dias que cumprem a Hora Pedagógica. As oficinas trabalham os descritores de Língua Portuguesa e Matemática que são avaliados na PROVA BRASIL.
} 
substituída, no Brasil, por uma escola nova; [...] Se voltarmos nosso olhar para o presente e focalizarmos os discursos sobre formação de professores, perceberemos a permanência de muitos princípios disseminados no seio do escolanovismo". (COUTNHO-SOMMER, 2011, p.96)

Temos, então, esse ideal escolanovista, agora sob o primado do Construtivismo pedagógico, perpassando pelas principais políticas curriculares implantadas no Brasil desde a segunda metade da década de 1990 com a aprovação da LDBEN de 1996, os Parâmetros Curriculares de 1997, posteriormente as Diretrizes curriculares nacionais em 2013 e em 2017 a BNCC.

Os autores encerram seu artigo afirmando que a docência hoje se transformou como ação de governar a sala de aula, de organizar e dirigir aprendizagens prescritas. Assim, diante do exposto até o momento é possível afirmar que as políticas curriculares tanto em nível macro, como a homologação da BNCC e do novo Ensino Médio que impõe novas trajetórias formativas aos jovens, como o nível micro, ou seja, aquelas praticadas pelos professores no âmbito das salas de aula fazem parte da engrenagem escolar e as práticas discursivas dos currículos apontam para o governamento para uma sociedade neoliberal que delineia os que deverão governar e aqueles que serão governados.

A vigilância cada vez maior ao trabalho docente realizada por especialistas das secretarias de educação, gestores escolares e até mesmo pelas famílias por resultados está na ordem da Governamentalidade neoliberal, já que de acordo com Peters (1994, p. 213) "não existe melhor exemplo da extensão do mercado a novas áreas da vida social que a educação. É claro que, sob os princípios do neoliberalismo, a educação tem sido discursivamente reestruturada de acordo com a lógica do mercado".

Um espaço, portanto, muito importante para um mercado que, cada vez mais, invade o campo da educação com produtos tecnológicos (computadores, tabletes, projetores etc.) livros, materiais pedagógicos entre tantos outros que fazem parte indispensável da agenda neoliberal para educação, inclusive determinando desresponsabilização do Estado com seu dever assegurado nos dispositivos legais de garantir educação para todos.

Nessa lógica, o Governo do estado do Pará estabeleceu a Parceria Público x Privado (PPP) com o suposto intuito de melhorar os péssimos resultados nas avaliações nacionais, tendo em vista que o Pará, nesse ranking, está entre os piores do Brasil.

No que concerne ao projeto Mundiar do Pará, o imperativo contextual histórico que propiciou o seu surgimento foram os índices educacionais do estado nas avaliações de larga escala do Governo Federal. As notas apontadas pelo Índice de Desenvolvimento da Educação Básica 
(Ideb), conforme já exposto anteriormente, colocam a educação do Estado do Pará como uma das piores do Brasil.

Com relação ao Ideb, as bases que compõe as suas notas são os índices de evasão e repetência dos sistemas de ensino, aliado as notas das avaliações nacionais. Assim, ao promover a promoção destes alunos para os níveis maiores do ensino, de uma só vez, o Governo do Estado, valendo-se do saber-poder da Estatística, consegue se desresponsabilizar pela educação desses alunos cunhados como atrasados e tenta melhorar (ou seria mesmo maquiar) a qualidade da educação perante os dados nacionais.

Desta forma, no processo de implantação do Mundiar nas escolas, a primeira tarefa era selecionar os alunos que se encontravam em distorção idade x série e que estavam cursando o $6^{\circ}$ e o $7^{\circ}$ ano do Ensino Fundamental e o $1^{\circ}$ ano do Ensino Médio. E quem foram os alunos selecionados?

Com os dados obtidos na pesquisa de campo realizada numa escola de periferia de Belém do Pará, nessa triagem, foram selecionados noventa alunos que fariam parte do projeto em três turmas: duas para o ensino fundamental e outra para o ensino médio.

O grande objetivo do projeto era permitir a estes discentes a conclusão dos respectivos níveis de ensino em um ano e oito meses. Portanto, trata-se de um projeto de aceleração da aprendizagem. (acelerar? Ou disciplinar?).

Em sua tese de doutorado Morgenstern (2016) discute a produção de subjetividades em práticas de correção da aprendizagem. De forma provocativa, lança os seguintes questionamentos: “Como seria possível acelerar a aprendizagem? Como tais propostas pedagógicas funcionam para atingir esse proposito? Ainda: por que são nomeados desta forma, e não como programas de ensino para alunos em defasagem escolar, por exemplo?” (MORGENSTERN, 2016, p. 21).

É importante destacar que este projeto da Secretaria Estadual de Educação do Pará conta com o apoio da Fundação Roberto Marinho que disponibilizou para as escolas as aulas em DVD além das televisões de LED. As aulas são no formato de Telecurso que, assim, disponibiliza os conteúdos curriculares que serão apresentados aos alunos.

A metodologia apresentada, então, para acelerar a aprendizagem dos alunos é apresentada como atraente e de acordo com a necessidade deles.

É válido ressaltar que os alunos que estão nesta trama educativa denominada de aceleração da aprendizagem e que são sujeitos cujas narrativas se enredam para situações de exclusão social e até mesmo categorização/juízos de valor, visto que em sua maioria são alunos com trajetórias de 
repetência, abandono e situações dramáticas em seu meio social. Em outras palavras, eram em sua maioria negros, mulheres que engravidaram na adolescência, filhos de "bandidos" e toda tessitura semântica que expurga as diferenças. Os alunos escolhidos foram os que eram rotulados como os alunos problemas pelos profissionais da escola, incluindo os docentes.

A par disso, os sujeitos selecionados a participar do projeto Mundiar são aqueles que estão em defasagem idade x série/ano, em outras palavras, que repetiram varias vezes a mesma série e que estão na iminência de se evadirem (expulsos?) do sistema regular de ensino. Ou seja, estes alunos já estão rotulados como fracassados, sendo atribuídos diversos juízos de valor, os principais versam acerca de suas origens sociais, étnicas, gênero, familiares...

\section{A INVENÇÃO DO ALUNO COM PROBLEMA IDADE X SÉRIE}

É no contexto neoliberal que emerge a partir da segunda metade da década de 90, principalmente com a aprovação da Lei 9.394/96, a LDBen, a ideia de Acelerar a aprendizagem, com o discurso de ser o "remédio" para curar um problema persistente nas redes de ensino: O fracasso escolar e o não fluxo de alunos que onera economicamente o estado, gerando, assim, o aluno em distorção idade série.

Para começar a discussão em torno da invenção do aluno em defasagem idade $\mathrm{x}$ série. Vejamos o que está exposto nos dispositivos legais da educação que o permitiram emergir.

A Constituição Federal de 1988 em seu artigo 205 define a educação como "direito de todos e dever do Estado e da família, será promovida e incentivada com a colaboração da sociedade, visando ao pleno desenvolvimento da pessoa, seu preparo para o exercício da cidadania e sua qualificação para o trabalho".

E mais a frente, no artigo 208, alínea I, define que a educação básica é “obrigatória e gratuita dos quatro aos dezessete anos de idade, assegurada inclusive sua oferta gratuita para todos os que a ela não tiveram acesso na idade própria” (Redação dada pela Emenda Constitucional 59, de 2009).

Outro dispositivo legal importante foi à promulgação da Lei 11.274/2006 que alterou o artigo 32 da LDB e estabeleceu o Ensino fundamental no Brasil de 9 anos, devendo a criança ser matriculada aos 6 anos no primeiro ano e concluir o nono ano aos 14 anos, seguindo posteriormente para os 3 anos finais da Educação Básica que é o Ensino Médio. (BRASIL, 2006).

Os dispositivos apresentados acima que organizam a oferta do ensino obrigatório no Brasil conceberam um caminho formativo que começa na infância e termina na juventude dos sujeitos. 
Menezes (2015), a partir dos estudos de Foucault, assevera que o século XVIII estabeleceu um novo lugar para a infância com a organização de um novo modelo social no qual o poder do soberano é substituído pelo governo das condutas através dos saberes, como a Psicologia, do homem que será constituído um modelo de observação, mensuração e estimulação das condutas cuja vigilância será constante para definir uma função normalizadora.

Desta forma, a normatização dos tempos escolares no Brasil é oriunda dos saberes Psicológicos que determinam o que cada criança ou jovem deve aprender ao longo da trajetória formativa de acordo com a sua fase de desenvolvimento. A par disso "Esta coincidência entre as expectativas psicopedagógicas e as fases de desenvolvimento da criança torna possível a emergência de uma regulamentação para cada período do desenvolvimento infantil. [...] A Psicologia, portanto, participa, concorre e promove a eficácia do aparelho educativo. (MENEZES, 2015 , p. 9). A criança que se desvia dessa matriz normalizadora torna-se anormal, patológica ou inassimilável ao sistema educativo devendo ser corrigido.

A par disso, o aluno em defasagem escolar ou distorção idade x série é uma invenção que emerge no contexto da escola moderna, em que os saberes da Psicologia foram fundamentais para considerar que é considerado atrasado o educando cuja idade não está compatível em seu itinerário formativo escolar, isto é, com a série recomendada para a sua idade, seja por diversos motivos, tais como: inúmeras repetências; evasões e/ou outras situações que o colocam numa condição de atraso e, por conseguinte, gerando um problema para o fluxo escolar e para a economia dos governos, surgindo assim, a necessidade de acelerá-lo. 


\section{CONCLUSÃO}

Ao longo deste artigo buscamos entrelaçar as teias que constituem a rede discursiva entre as avaliações de larga escala e seus efeitos no currículo da escola básica e como isso se constitui para produzir o aluno com distorção idade x série.

A educação escolar é palco de muitas disputas políticas e que ao longo da sua história tem sido uma importante engrenagem do modo de produção capitalista. Ao realizarmos uma genealogia de sua emergência histórica, percebemos que a escola foi constituída historicamente para servir ao grande capital, assumindo diversas facetas a medida que as crises do capitalismo moldam novas formas de pensar e agir.

Contudo, existem linhas de fugas que são urdidas no cotidiano da escola pelos profissionais da educação comprometidos com as causas populares e que imprimem uma grande luta em busca da construção de uma escola gratuita e de qualidade, ainda que a despeito disso, sejam implantadas propostas que visam à desobrigação do estado com a educação básica, o que, aliás, vem ocorrendo de forma sistemática com o atual movimento conservador que assola o país, no qual a própria concepção de educação básica hoje se encontra em grande perigo.

É seguindo esta lógica que o controle da suposta qualidade da escola verificada através das avaliações nacionais está contido na agenda neoliberal do estado mínimo em que serviços essenciais à população são entregues ao mercado, cabendo ao estado somente sua regulação e controle. Não há, portanto, uma preocupação com as pessoas que acabam sendo tratadas como "coisas" que precisam ser moldadas para garantir a manutenção do status quo e as condições materiais que garantem a relação de subserviência da maioria da população as gritantes injustiças sociais que acontecem em nosso país.

Nesta perspectiva, urge pensar numa educação outra que garanta justiça social ao povo brasileiro, principalmente os que mais necessitam da escola pública gratuita e de qualidade, que são os excluídos das benesses sociais e que em tese são os únicos beneficiários dela. Não apenas oferecer o mínimo, como se isto fosse um favor que os governantes cumprem com o povo. Pensar na lógica da avaliação e do currículo na perspectiva mesmo da humanidade desses alunos em vias de expulsão da escola porque a mesma não atende e historicamente nunca atendeu as reais necessidades dos alunos de escola pública. 


\section{REFERÊNCIAS}

ANDERSON, P. Balanço do neoliberalismo. In: SADER, E.; GENTILI, P. (Orgs.) Pós-neoliberalismo: as políticas sociais e o Estado democrático. Rio de Janeiro: Paz e Terra, 1995.

ANPED. Nota da ANPED: sobre a entrega da terceira versão da Base Nacional Comum Curricular ao Conselho Nacional de Educação (CNE), São Paulo, 2017.

BRASIL. Constituição (1988). Constituição da República Federativa do Brasil. Diário Oficial da União. Brasília: Congresso Nacional, 05 out. 1988. Anexo

. Lei 9.394, de 20 de dezembro de 1996. Estabelece as diretrizes e bases da educação nacional. Diário Oficial da União. Brasília: Poder Legislativo, 23 dez. 1996, sec. I, n. 248, p. 27.833.

. Ministério da Educação. Base Nacional Comum Curricular - BNCC 3a versão. Brasília, DF, 2017.

Lei 11.274, 6 de fevereiro de 2006. Dispõe sobre a duração de nove anos para o ensino fundamental, com matrícula obrigatória a partir dos seis anos de idade. Diário Oficial da União, Brasília, DF, 7 fev. 2006. Disponível em: www.senado.gov.br. Acesso em 27 de junho de 2018.

COUTINHO, K. D., ;SOMMER, L. H. Discursos sobre formação de professores e arte de governar. Currículo sem Fronteiras, 2011: 86-103.

FOUCAULT, M. Microfísica do poder. Org. e trad. Roberto Machado. 2. ed. Rio de Janeiro: Paz e Terra, 2015

Vigiar e punir: O nascimento da prisão. 42. ed. Petrópolis: Vozes, 2014.

GREGORIN, M. R. O dispositivo escolar. 2017. (47m17s.). Disponível em:〈https://youtu.be/.TdVYvrh-JfA>. Acesso em: 13 jun. 2018.

INEP. Resultados do SAEB 2015. Brasília, 2016. Disponível em http: <//www.inep.gov.br. Acesso em 16 de jun. 2018.

LE GOFF, J. História e memória. São Paulo: Ed. Unicamp, 2013.

LOPES, A.C. Democracia nas políticas de currículo. Cadernos de Pesquisa v.42 n.147 p.700-715 set./dez. 2012

MENEZES, J.E.X.. A psicologia como ferramenta política no processo de sujeição da criança. Cadernos do CEAS, Salvador, n. 235, p. 172-185, 2015.

MORGENSTERN, J. M. Práticas de correção e aprendizagem: produção de subjetividades na contemporaneidade. Tese (doutorado) - Universidade do Vale do Rio dos Sinos, Programa de Pós-Graduação em Educação, 2016.

PETERS, M. Governamentalidade neoliberal e Educação. In: SILVA, Tomaz T. O sujeito da educação. Petrópolis: Vozes, 1994. p. 211-224.

POPKETWITZ, T. História do Currículo, regulação Social e Poder. In: SILVA, Tomaz Tadeu. O sujeito da educação. Petrópolis: Vozes, 1994. p.173-210.

OPKEWITZ, T. Ciências da educação, escolarização e abjeção: diferença construção da desigualdade. Educ. Real., Porto Alegre, v. 35, n. 3, p. 77-98, set./dez., 2010.

VARELA, J.; ALVAREZ-URIA, F. A maquinaria escolar. Teoria e educação. Porto Alegre: Pannonica , n. 6, 1992.

VEIGA-NETO, A.; SARAIVA, K. Educar como arte de governar. Currículo sem Fronteiras, v. 11, n. 1, p.5-13, Jan./Jun. 2011. 


\section{RESUMO}

Este artigo tem a finalidade de discutir a relação entre as avaliações nacionais no Brasil com o currículo da escola básica e a produção do aluno com distorção idade x serie que, no cotidiano escolar, recebe a cunha de fracassado. Buscar-se-á, primeiramente uma abordagem genealógica da escola para evidenciá-la como uma invenção inscrita num imperativo histórico que garantiu sua emergência. Num segundo momento discute-se a avaliação como indutora do currículo e na fabricação do aluno problema a partir da pesquisa realizada em um projeto de aceleração numa escola de periferia em Belém do Pará. Os resultados apontam a necessidade de pensar alternativas às politicas homogeneizantes que negam a singularidade da pessoa humana e as possiblidades de uma educação que valorize as diferenças.

Palavras-chave: Avaliação; currículo; aluno problema.

\section{NATIONAL EVALUATIONS, CURRICULUM OF THE BASIC SCHOOL AND THE PRODUCTION OF THE STUDENT WITH DISTORTION AGE X SERIES.}

\section{ABSTRACT}

This article has the purpose of discussing the relationship between the national evaluations in Brazil with the curriculum of the basic school and the production of the student with age $x$ series distortion that, in the daily school, receives the wedge of failure. A genealogical approach of the school will be sought first to show it as an invention inscribed in a historical imperative that guaranteed its emergence. In a second moment, we discuss the evaluation as a curriculum-inducer and in the production of the problem student from the research carried out in an acceleration project in a peripheral school in Belém do Pará. The results point out the need to think of alternatives to the homogenizing policies that deny the uniqueness of the human person and the possibilities of an education that values differences.

Keywords: Evaluation; curriculum; student problem.

\section{EVALUACIONES NACIONALES, CURRÍCULO DE LA ESCUELA BÁSICA Y LA PRODUCCIÓN DEL ALUMNO CON DISTORSIÓN EDAD X SERIE.}

\section{RESUMEN}

Este artículo tiene la finalidad de discutir la relación entre las evaluaciones nacionales en Brasil con el currículo de la escuela básica y la producción del alumno con distorsión edad $\mathrm{x}$ serie que en el cotidiano escolar recibe la cuña de fracasado. Se buscará, primero, un enfoque genealógico de la escuela para evidenciarla como una invención inscrita en un imperativo histórico que garantizó su emergencia. En un segundo momento se discute la evaluación como inductora del currículo y en la fabricación del alumno problema a partir de la investigación realizada en un proyecto de aceleración en una escuela de periferia en Belém do Pará. Los resultados apuntan la necesidad de pensar alternativas a las políticas homogeneizantes que niegan la singularidad de la persona humana y las posibilidades de una educación que valorice las diferencias.

Palabras clave: evaluación; plan de estudios; el alumno problema. 